\title{
Changes in groundwater level associated with the 2003 Tokachi-oki earthquake
}

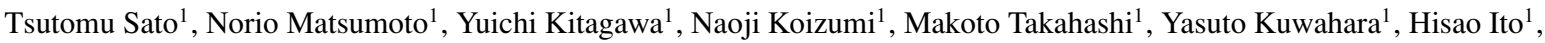 \\ Akio Cho ${ }^{1}$, Takashi Satoh ${ }^{1}$, Kunio Ozawa ${ }^{2}$, and Shigeki Tasaka ${ }^{3}$ \\ ${ }^{1}$ Geological Survey of Japan, AIST, 1-1-1 Higashi, Tsukuba, Ibaraki 305-8567, Japan \\ ${ }^{2}$ Shizuoka Prefectural Government, 9-6 Ote-machi, Shizuoka, Shizuoka 420-8601, Japan \\ ${ }^{3}$ Gifu University, 1-1 Yanagido, Gifu, Gifu 501-1193, Japan
}

(Received December 8, 2003; Revised February 5, 2004; Accepted February 18, 2004)

\begin{abstract}
Groundwater level and flow rate at 44 wells are continuously observed by the Geological Survey of Japan and the Shizuoka and Gifu Prefectural Governments for monitoring seismic and volcanic activities. The 2003 Tokachi-oki earthquake (M8.0) occurred off the south coast of Hokkaido Island, Japan on September 26, 2003. The epicentral distance to the nearest observation well is about $250 \mathrm{~km}$ and that to the farthest is about $1200 \mathrm{~km}$. At the 22 wells, we detected changes in groundwater level or flow rate in relation to the earthquake. Most of the changes are coseismic step-like changes and/or short-period oscillations. In the nearest two observation wells, long-period oscillations with the periods of 39 and 53 minutes were also observed for several days after the earthquake, which is likely due to tsunami. In comparison between distributions of changes in groundwater level and theoretical coseismic strain by the fault model, it is clear that step-like increases were found in the contraction area of the coseismic strain. The relationship between amounts of the observed step-like groundwater-level changes and theoretical ones, calculated by the fault model using strain sensitivities of groundwater level indicates that the groundwater levels in the several wells responded to the coseismic strain.
\end{abstract}

Key words: Groundwater level, flow rate, 2003 Tokachi-oki earthquake, coseismic strain, oscillation, tsunami.

\section{Introduction}

Earthquake-related groundwater-level changes have been reported for many earthquakes (e.g. Wakita, 1975; Roeloffs, 1988, 1996; Igarashi and Wakita, 1991; Akita and Matsumoto, 2001). In such studies, the groundwater-level changes were quantitatively compared with coseismic strain based on elasticity of porous media. The results showed that some of the changes were consistent with the crustal strain, and some were not. In most cases of inconsistencies, it is thought that other effects such as local permeability change and seismic oscillation interfere in the poroelastic process. Therefore, to use groundwater level as a coseismic strain indicator, we must evaluate the observation wells whether such interfering effects frequently appeared or not.

We can estimate the strain sensitivity of groundwater level based on tidal analysis any time. There are, however, fewer opportunities to detect the presence of interfering effects. Thus it is important to investigate the response of groundwater-level to large earthquakes.

After the 1995 Kobe earthquake, many observation wells were established in the central area of Japan. Strain sensitivities of groundwater level in these wells were investigated based on tidal analysis by Koizumi et al. (1999). Further, coseismic and/or postseismic changes of the groundwater levels were observed in relation to two recent large earthquakes: the 2000 western Tottori earthquake (M7.3) and the 2001 Geiyo earthquake (M6.7). Takahashi et al.

Copy right(c) The Society of Geomagnetism and Earth, Planetary and Space Sciences (SGEPSS); The Seismological Society of Japan; The Volcanological Society of Japan; The Geodetic Society of Japan; The Japanese Society for Planetary Sciences; TERRAPUB.
(2002) and Koizumi et al. (2002) reported the groundwaterlevel changes and discussed relations between the changes and coseismic strain, respectively. The results show that groundwater-level responses in some wells are consistent with coseismic strain but that those in some wells are not. Similar groundwater-level changes were observed in relation to the latest large earthquake, the 2003 Tokachi-oki earthquake (M8.0). In this paper, we will report the changes and compare the changes with the coseismic strain as well as the previous two large earthquakes. If the consistencies between groundwater-level changes and coseismic strain have been observed in particular wells, it can be stated that the wells are useful to observe coseismic strain. Such information is very important to observe the groundwater level for monitoring earthquake activities.

The 2003 Tokachi-oki earthquake (M8.0) occurred off the Tokachi area of Hokkaido Island, Japan, at 04:50 JST on 26 September 2003 (Fig. 1; Yamaoka and Kikuchi, 2003). The fault model calculated by Geographical Survey Institute using the GPS data (Geographical Survey Institute, 2003) is represented in Fig. 1 by a hatched square. The model shows the depth, length, width, dip angle and slip of the earthquake as $19.7 \mathrm{~km}, 85.7 \mathrm{~km}, 83.0 \mathrm{~km}, 22$ degrees and $5.19 \mathrm{~m}$, respectively.

This large slip caused tsunami along the south coast of Hokkaido Island broadly. The height of the tsunami was $1 \mathrm{~m}$ near the fault, which was observed at the several tidal observatories by Japan Meteorological Agency, Japan Coast Guard and Hokkaido Development Bureau (Japan Meteorological Agency, 2003). The tsunami continued for half a day at least with relatively long-period oscillations of 30-60 min- 


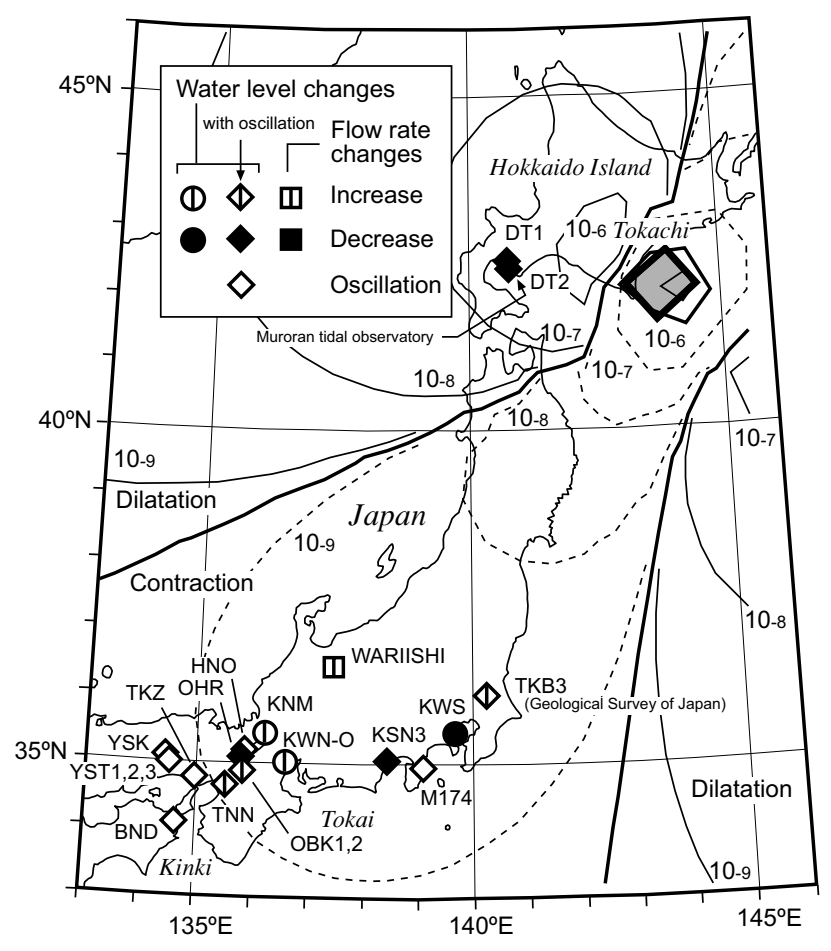

Fig. 1. Location of observation wells (circles, diamonds and squares). A hatched square indicates the fault model of the 2003 Tokachi-oki earthquake by the Geographical Survey Institute (2003). Contours denote the calculated volumetric strain by the fault model.

utes. For example, nearly 1-hour-period oscillation was observed at the Muroran tidal observatory of the Japan Coast Guard, and the oscillation started about one hour after the earthquake (Fig. 2(a)).

Aftershocks were distributed broadly NE to SW of 150 $\mathrm{km}$ and NW to SE of $100 \mathrm{~km}$ (Japan Meteorological Agency, 2003). The largest aftershock (M7.1) occurred about $30 \mathrm{~km}$ west from the main shock at 06:08 JST, one hour and 18 minutes after the main shock.

\section{Groundwater-Level Observations}

Groundwater-level observation at 42 wells was performed for monitoring seismic and volcanic activities by the Geological Survey of Japan (Table 1). The central observation network was established in the Tokai district (Fig. 1) in the 1970's for monitoring the coming Tokai earthquake. Since 1994 , the number of the observation wells increased because of large seismic and volcanic events. For example, the observation wells in the Kinki district were drilled after the Kobe earthquake with M7.2 (Koizumi et al., 1999), and new instruments were equipped at DT1 and DT2 in Hokkaido Island after the 2000 eruption of the Usu Volcano (Matsumoto et al., 2002). For the same purpose, Shizuoka and Gifu Prefectural Governments have also observed groundwater levels and flow rates.

The nearest observation wells, DT1 and DT2 are located in Hokkaido Island about $250 \mathrm{~km}$ west from the epicenter of the earthquake (Fig. 1). Both wells were drilled $4 \mathrm{~km}$ apart each other for monitoring water resources in 1994. On March 2000, significant increases of groundwater level were observed in both wells in relation to volcanic activity of the
Table 1. Description of 42 observation wells of GSJ, AIST.

\begin{tabular}{|c|c|c|c|c|c|c|}
\hline well & $\begin{array}{c}\text { Location of well } \\
\text { latitude, longtitude, altitude }\end{array}$ & $\begin{array}{c}\text { casing } \\
\text { diameter }(\mathrm{mm}) \\
\end{array}$ & $\begin{array}{c}\text { well } \\
\text { depth }(m)\end{array}$ & $\begin{array}{l}\text { screened } \\
\text { depth }(\mathrm{m})\end{array}$ & geology & $\begin{array}{c}\text { well water level } \\
\text { (m above SL) }\end{array}$ \\
\hline$\overline{\text { ATS }}$ & $36.418^{\circ} \mathrm{N}, 137.313^{\circ} \mathrm{E}, 350$ & 150 & & & PTs & \\
\hline BND & $34.141^{\circ} \mathrm{N} \quad 134517^{\circ} \mathrm{E} \quad 25$ & 200 & 502 & $419-430$ & Os & 25 \\
\hline DIT & $34.663^{\circ} \mathrm{N}, 138.058^{\circ} \mathrm{E}, 5$ & 200 & 260 & $145-222$ & Qs & 5 \\
\hline DT1 & $42.486^{\circ} \mathrm{N}, 140.843^{\circ} \mathrm{E}, 5$ & 250 & 180 & $\begin{array}{l}136-147 \\
164-175\end{array}$ & $\mathrm{Qs}$ & 3 \\
\hline DT2 & $42.465^{\circ} \mathrm{N}, 140.874^{\circ} \mathrm{E}, 7$ & 250 & 180 & $\begin{array}{c}80-92 \\
103-114\end{array}$ & Qs & 5 \\
\hline GOJ & $34.387^{\circ} \mathrm{N}, 135.707^{\circ} \mathrm{E}, 236$ & 200 & 334 & $313-330$ & PTv & 220 \\
\hline $\mathrm{HAI}$ & $34.790^{\circ} \mathrm{N}, 138.189^{\circ} \mathrm{E}, 58$ & 200 & 171 & $71-154$ & Ts & 56 \\
\hline HKS-I & $35.123^{\circ} \mathrm{N}, 136.507^{\circ} \mathrm{E}, 116$ & 200 & 511 & $491-511$ & Qs & 95 \\
\hline HKS-O & $35.123^{\circ} \mathrm{N}, 136.507^{\circ} \mathrm{E}, 116$ & 400 & 290 & $\begin{array}{l}100-110 \\
184-215\end{array}$ & $\begin{array}{l}\text { Qs } \\
\text { Qs }\end{array}$ & 112 \\
\hline & & & & $258-269$ & Qs & \\
\hline HKW & $34.911^{\circ} \mathrm{N}, 139.053^{\circ} \mathrm{E}, 39$ & 200 & 152 & $130-147$ & $\mathrm{Tv}$ & 27 \\
\hline HMO & $34.631^{\circ} \mathrm{N}, 138.158^{\circ} \mathrm{E}, 35$ & 200 & 270 & $154-264$ & Ts & 21 \\
\hline HNO & $35.186^{\circ} \mathrm{N}, 135.857^{\circ} \mathrm{E}, 262$ & 150 & 476 & $235-246$ & PTs & 294 \\
\hline HRB & $34.580^{\circ} \mathrm{N}, 134.972^{\circ} \mathrm{E}, 36$ & 150 & 747 & $630-650$ & PTv & 32 \\
\hline HTS & $35.151^{\circ} \mathrm{N}, 136.256^{\circ} \mathrm{E}, 125$ & 200 & 515 & $338-360$ & Qs & 118 \\
\hline IKD & $34.816^{\circ} \mathrm{N}, 135.439^{\circ} \mathrm{E}, 35$ & 200 & 680 & & Qs & 10 \\
\hline ING & $34.887^{\circ} \mathrm{N}, 135.374^{\circ} \mathrm{E}, 85$ & 150 & 1000 & $700-823$ & PTs & 82 \\
\hline KNG1 & $34.988^{\circ} \mathrm{N}, 138.435^{\circ} \mathrm{E}, 21$ & 200 & 320 & $309-320$ & Ts & 19 \\
\hline KNG2 & $34.987^{\circ} \mathrm{N}, 138.433^{\circ} \mathrm{E}, 21$ & 200 & 250 & $224-235$ & Qs & 20 \\
\hline KNG3 & $34.988^{\circ} \mathrm{N}, 138.434^{\circ} \mathrm{E}, 21$ & 200 & 31 & $8-20$ & Qs & 19 \\
\hline KNM & $35.495^{\circ} \mathrm{N}, 136.215^{\circ} \mathrm{E}, 110$ & 200 & 250 & $178-195$ & Qs & 108 \\
\hline KWN-I & $35.073^{\circ} \mathrm{N}, 136.652^{\circ} \mathrm{E}, 76$ & 200 & 300 & $264-280$ & Qs & 28 \\
\hline KWN-O & $35.073^{\circ} \mathrm{N}, 136.652^{\circ} \mathrm{E}, 76$ & 350 & 100 & $\begin{array}{l}67-84 \\
809819\end{array}$ & Qs & 46 \\
\hline KWS & $35.524^{\circ} \mathrm{N}, 139.714^{\circ} \mathrm{E}, 10$ & 250 & 1016 & $\begin{array}{c}809-819 \\
861-1012\end{array}$ & $\begin{array}{l}\text { Ts } \\
\text { Ts }\end{array}$ & 1 \\
\hline NGR & $34.279^{\circ} \mathrm{N}, 135.331^{\circ} \mathrm{E}, 90$ & 200 & 625 & $402-446$ & Qs & 16 \\
\hline & $35.215^{\circ} \mathrm{N}, 136.616^{\circ} \mathrm{E}, 12$ & 200 & 458 & $427-$ & Qs & \\
\hline OBK1 & $34.908^{\circ} \mathrm{N}, 135.811^{\circ} \mathrm{E}, 52$ & 200 & 389 & $357-374$ & PTs & 46 \\
\hline $\mathrm{OBK} 2$ & $34.909^{\circ} \mathrm{N}, 135.814^{\circ} \mathrm{E}, 59$ & 200 & 122 & $96-113$ & PTs & 65 \\
\hline OGS & $34.696^{\circ} \mathrm{N}, 138.085^{\circ} \mathrm{E}, 8$ & 200 & 150 & $128-145$ & Qs & 8 \\
\hline OHR & $35.107^{\circ} \mathrm{N}, 135.822^{\circ} \mathrm{E}, 217$ & 150 & 272 & $256-267$ & PTv & 210 \\
\hline OMR & $34.913^{\circ} \mathrm{N}, 139.092^{\circ} \mathrm{E}, 245$ & 200 & 152 & $130-146$ & $\mathrm{Tv}$ & 219 \\
\hline SED & $34.317^{\circ} \mathrm{N}, 134.748^{\circ} \mathrm{E}, 3$ & 200 & 253 & 210 & Qs & \\
\hline SGR & $36.348^{\circ} \mathrm{N}, 137.185^{\circ} \mathrm{E}, 386$ & 150 & 298 & 257 & PTs & 363 \\
\hline THY & $34.763^{\circ} \mathrm{N}, 137.470^{\circ} \mathrm{E}, 77$ & 20 & 245 & & PTs & 68 \\
\hline THY & $34.763^{\circ} \mathrm{N}, 137.470^{\circ} \mathrm{E}, 77$ & 20 & 15 & & PTs & 66 \\
\hline TKB & $36.061^{\circ} \mathrm{N}, 140.135{ }^{\circ} \mathrm{E}, 25$ & $26>-2>>0$ & 66 & & Qs & -3 \\
\hline TKB3 & $36.061^{\circ} \mathrm{N}, 140.136^{\circ} \mathrm{E}$, & 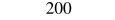 & 15 & & Qs & 3 \\
\hline TKZ & $34.818^{\circ} \mathrm{N}, 135.3$ & 15 & 1000 & & PTs & 110 \\
\hline TNN & $34.656^{\circ} \mathrm{N}, 135.515^{\circ} \mathrm{E}, 10$ & 20 & 603 & & Qs & -32 \\
\hline YSK & $35.018^{\circ} \mathrm{N}, 134.607^{\circ} \mathrm{E}, 150$ & 20 & 15 & & PTs & 171 \\
\hline YST1 & $34.982{ }^{\circ} \mathrm{N}, 134.611^{\circ} \mathrm{E}, 126$ & 200 & 280 & & PTs & \\
\hline YST2 & $34.982^{\circ} \mathrm{N}, 134.611^{\circ} \mathrm{E}, 126$ & 200 & 155 & $144-150$ & PTs & 142 \\
\hline$\underline{\text { YST3 }}$ & $34.982{ }^{\circ} \mathrm{N}, 134.611{ }^{\circ} \mathrm{E}, 126$ & 200 & 155 & 144-150 & PTs & 142 \\
\hline
\end{tabular}

SL: Sea Level, Qs: Quaternary sedimentary rocks, Ts: Tertiary sedimentary rocks, Tv: Tetiary volcanic rocks, SL: Sea Level, Qs: Quaternary sedimentary rocks, Ts: Tertiary sediment
PTs: Pre-Tertiary sedimentary rocks, PTv: Pre-Tertiary volcanic rocks.

Usu volcano located $6 \mathrm{~km}$ northwest from DT1 (Matsumoto et al., 2002). The total increases were consistent or less than those estimated by crustal strain due to magma movement using the strain sensitivity of groundwater level.

The other observation wells are located in and around the Tokai and Kinki districts, which are about 1,000 km and 1,200 km apart from the epicenter, respectively (Fig. 1). In some sites, there are several wells whose depths are different. For example, there are four wells in TKB, three wells in KSN, two wells in OBK and three wells in YST, and we named the No. 3 well in TKB as "TKB3". Two pipes whose diameters are large and small were installed concentrically in a well at KWN. We named the inner and outer pipes as "KWN-I" and "KWN-O", respectively. Koizumi et al. (1999) introduced these wells in the Kinki district and discussed the strain sensitivities of groundwater level.

We have been observing water level, water temperature, atmospheric pressure and rainfall. The data of atmospheric pressure and rainfall are used to correct that of water level. The sampling interval was two minutes, and the data were transmitted to the Geological Survey of Japan (TKB in Fig. 1) via phone line once a day or once an hour.

Observations at the two wells, M174 and Wariishi were performed by Shizuoka and Gifu Prefectural Governments, respectively. The M174 well is located in the Ito hot spring $900 \mathrm{~km}$ away form the epicenter (Fig. 1). During near seismic and volcanic events in 1989 about $3 \mathrm{~km}$ apart from the hot spring, groundwater and hot-spring water flowed out before the volcanic eruption (Sato et al., 1992). The M174 well was one of them. The Shizuoka Prefectural Government started groundwater-level observation using an analog recorder in 1991, and the Geological Survey of Japan started a 2-minute digital sampling in 1998. On the other hand, the 

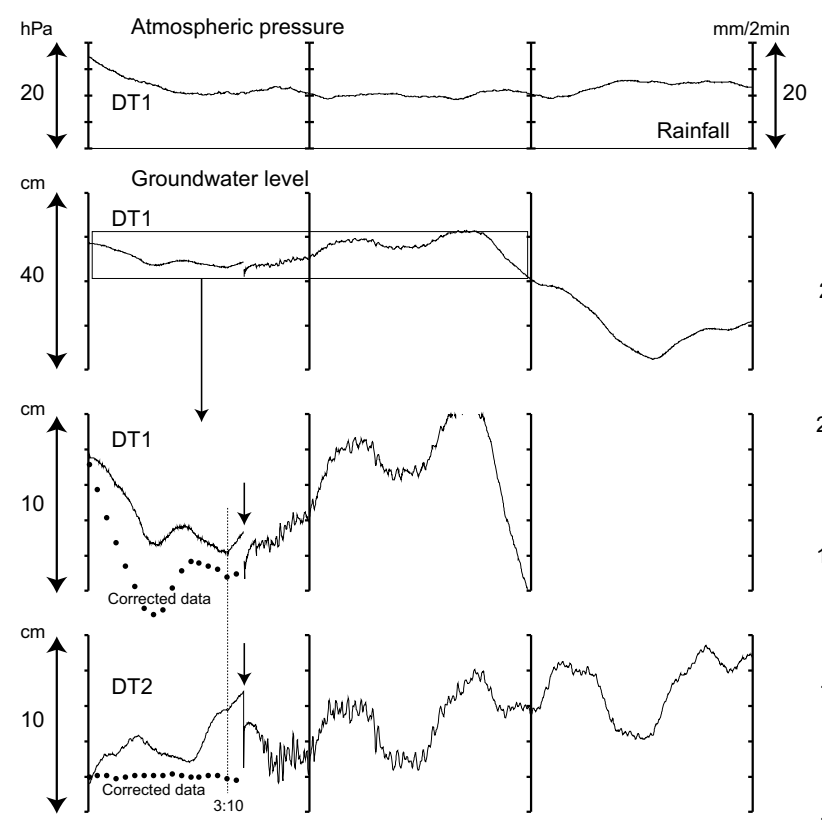

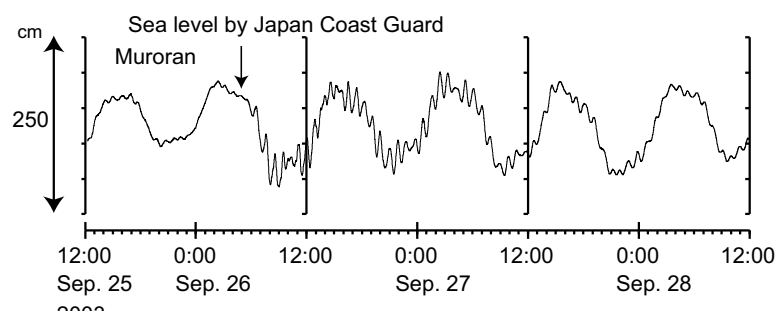

(a)
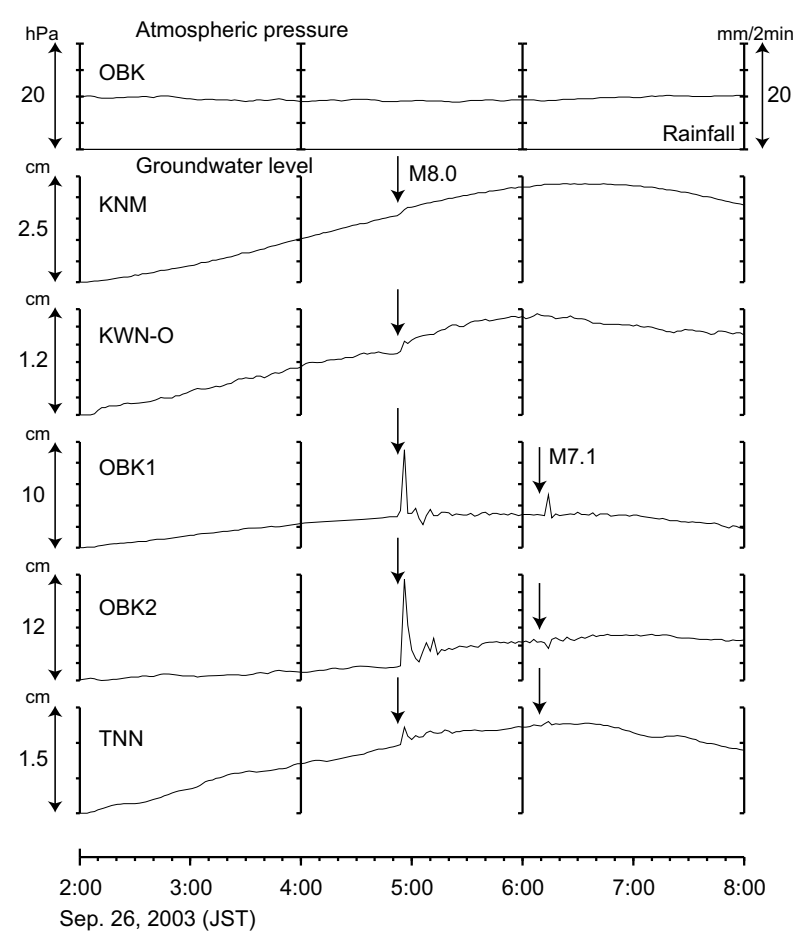

(c)

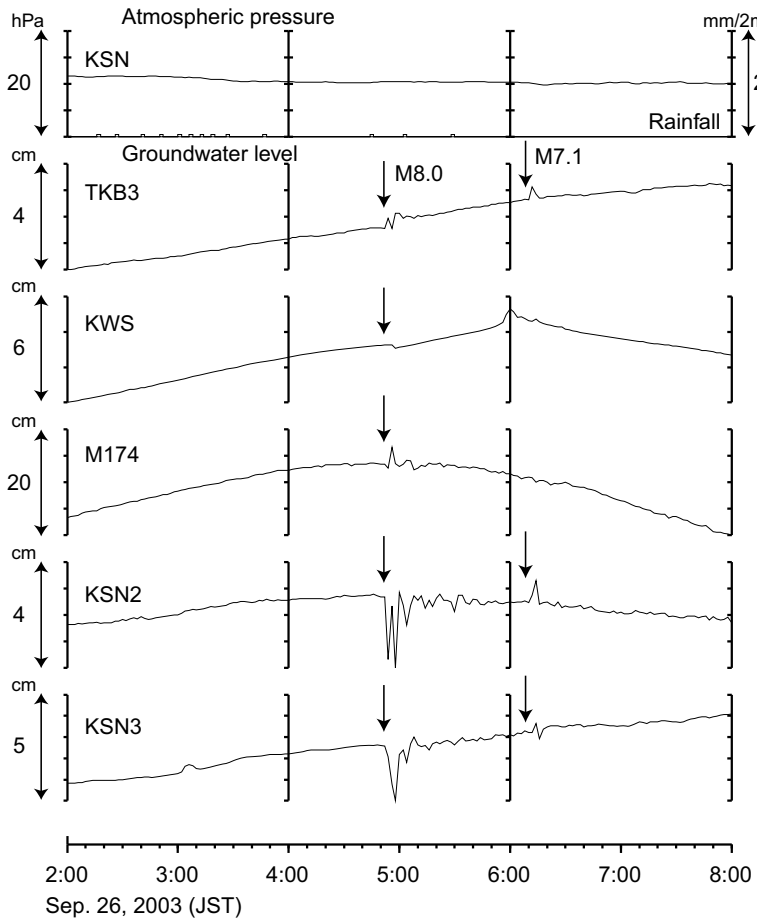

(b)
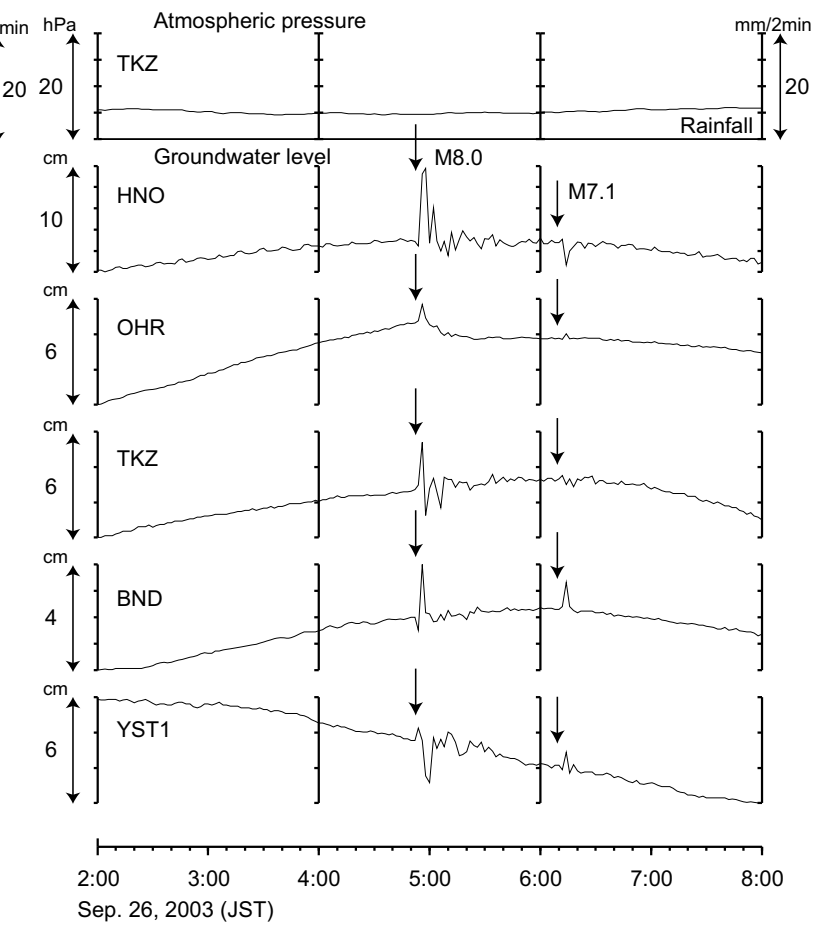

(d)

Fig. 2. 2-minute values of groundwater levels.

Wariishi well is located at the Wariishi hot spring $840 \mathrm{~km}$ apart form the epicenter (Fig. 1). The Gifu Prefectural Government have been observing flow rates in an artesian well using an electromagnetic flow meter since July 1998.

\section{Results}

Figure 2(a) shows three days' groundwater levels in DT1 and DT2. The water levels dropped at the earthquake, and immediately recovered about $30 \%$ and $60 \%$ of the maximum drops in DT1 and DT2, respectively. About two hours 


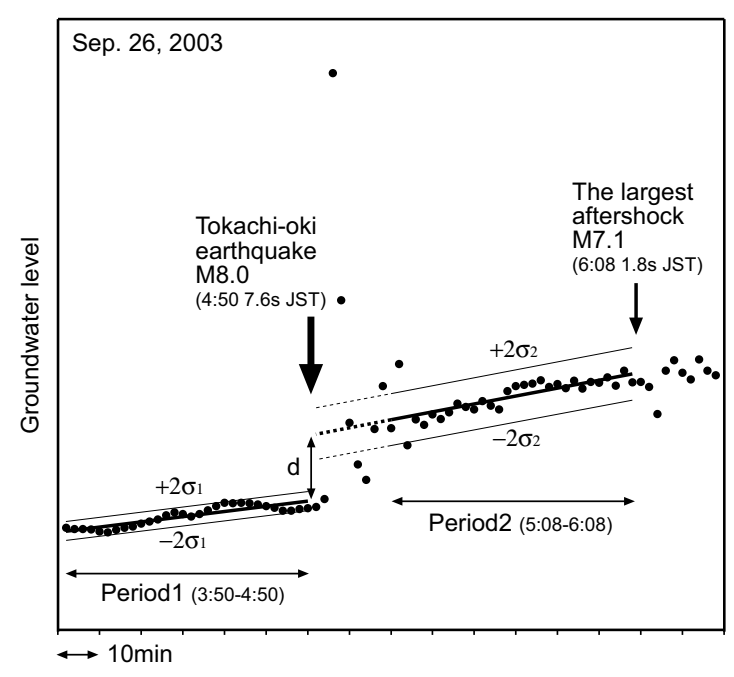

Fig. 3. Schematic diagram of coseismic groundwater-level changes.

after the earthquake, remarkable periodic oscillation in the groundwater levels started and continued for about one and three days in DT1 and DT2, respectively. The dominant periods of the oscillation are 39 and 53 minutes, which are entirely consistent in both wells. We also detected possible preseismic changes in the both wells. The groundwater levels gradually increased one hour and 20 minutes before the earthquake. The total increases until the earthquake are 12 $\mathrm{mm}$ in DT1 and $11 \mathrm{~mm}$ in DT2. It should be noted that the starting time and amount of the increases are almost same in the both wells. We could not, however, judge whether the changes are anomalous or not. In Fig. 2(a), the corrected data, for which tidal components and responses to atmospheric pressure are removed by BAYTAP-G (Tamura et al., 1991), are shown as solid circles. Calculations were performed using data of three months before the earthquake. The corrected data demonstrate that the preseismic changes of the both wells are not significant. Unfortunately only 1hour data are now available for the calculation of such corrected data as shown in Fig. 2(a). We continued to investigate the preseismic changes, for example recalculating the corrected data using the 2-minute data.

Figures 2(b), 2(c) and 2(d) show the 2-minute data from 2:00 to 8:00 on September 26, 2003, observed at the wells in the Tokai and Kinki districts. Most frequent changes related to the main-shock are groundwater-level oscillations which period is a few minutes or less. Coseismic step-like changes were also found in the some wells, such as KWS, KNO and KWN-O. Smaller groundwater-level oscillations also occurred at many wells in relation to the largest aftershock of M7.1.

Both changes of oscillation and step-like change were simultaneously observed in the some wells, such as OHR and OBK2. The step-like change in OHR is larger than the oscillation, and in contrast the oscillation is larger in OBK2. In the latter case, it is difficult to judge whether the step-like change is significant or not. Thus we specified a criterion to measure quantitative amount of step-like change as below.

Figure 3 shows a schematic diagram of a coseismic groundwater-level change in case that the oscillation is larger than the step-like change. First, we performed linear regression for one hour of Period 1 and Period 2; Period 1 is just before the main-shock, and Period 2 is just before the largest aftershock. Second, we calculated the residual standard deviations for both periods as $\sigma_{1}$ and $\sigma_{2}$, respectively. Due to the oscillation, the value of $\sigma_{2}$ is larger than $\sigma_{1}$ in Fig. 3. Finally, we defined the amount of the step-like change, $d$, as a difference between water levels at 4:50 and 4:52 predicted by the liner regressions of Period 1 and Period 2, respectively. When the value of $d$ was larger than $2 \sigma_{1}, 2 \sigma_{2}$ and $2 r$, we concluded that the step-like change was detectable. The $r$ is resolution of groundwater-level observation, and the value is $0.2 \mathrm{~mm}$ in many wells.

The 11 wells in which the coseismic step-like change was detectable, are DT1, DT2, KWS, KSN3, OHR, KNM, TKB3, KWN-O, OBK1, OBK2 and TNN (Fig. 1). The changes in the former 5 wells are decreases of groundwater level and those in the latter 6 wells are increases. On the other hand, there are several wells in the Tokai and Kinki districts for which only oscillation is observed.

Figure 4 shows a coseismic increase of the flow rate in the Wariishi well. The flow rate increased to $34.5 \mathrm{~L} / \mathrm{min}$ from $31.5 \mathrm{~L} / \mathrm{min}$ in relation to the main shock.

\section{Discussion}

The distribution of coseismic static strain calculated by the fault model is shown in Fig. 1. The calculation was performed using MICAP-G (Naito and Yoshikawa, 1999) based on Okada (1992). According to linear poroelasticity, groundwater-level decreases in the dilatation area and increases in the contraction area (Roeloffs, 1996). Coseismic groundwater-level changes in 8 of the examined 11 wells are consistent with coseismic strain steps, except in the three wells, KWS, KSN and OHR. The reason why different responses from the linear poroelasticity were observed in three wells is not obvious, however, it is clear that the responses were not reflected directly to the coseismic strain.

$10^{8}-10^{9}$ coseismic contraction is estimated at the wells with detectable step-like groundwater-level changes in the Tokai and Kinki districts. This coseismic contraction is consistent with the fact that the strain sensitivities of the many wells were calculated to be $0.5-1.5 \mathrm{~mm} / 10^{9}$ (Koizumi et al., 1999). The strain sensitivity indicates that strain sensitivities smaller than $10^{9}$ could not cause larger groundwater-level changes than $2 r$. In the area where the coseismic strain is less than $10^{9}$ (Fig. 1), the observed coseismic changes are expressed as groundwater-level oscillations only.

Figure 5 shows the relationship between the observed amount of the step-like groundwater-level changes, $Y$, and the theoretical ones, $X$, due to coseismic strain. The calculation for the latter was performed as follows; first, amplitude and phase of M2 tidal constituent were extracted from groundwater level for 6 months before the earthquake by BATAP-G. Second, strain sensitivities were calculated to divide the given amplitude of M2 tidal constituent by theoretical tidal strain at the wells. The theoretical tidal strain was calculated by GOTIC2 (Matsumoto et al., 2001). Finally, theoretical groundwater-level changes were determined by dividing the estimated coseismic strain by the strain sensitivity of the groundwater level. Error for $X$-axis in Fig. 5 


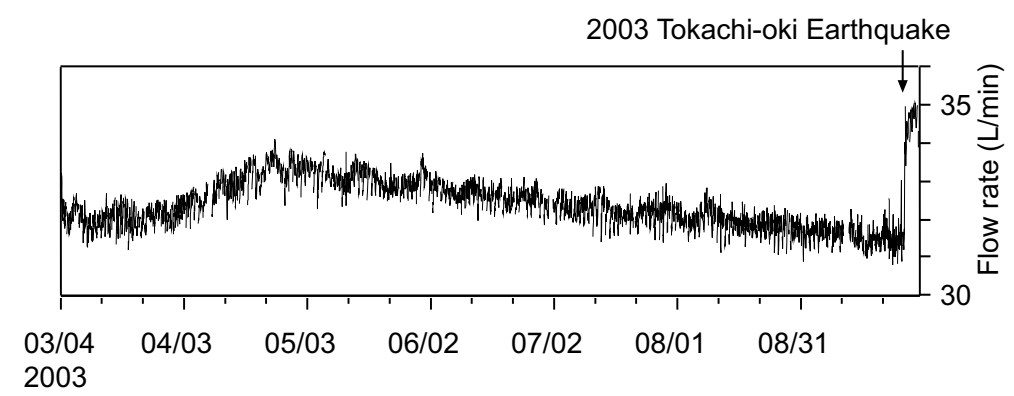

Fig. 4. Flow rate changes in Wariishi.

is mainly due to the estimated variance by BAYTAP-G. On the other hand, error for $Y$-axis shows the maximum value among $2 \sigma_{1}, 2 \sigma_{2}$ and $2 r$.

DT1 and DT2 are plotted below the line of $Y=0.1 X$ in Fig. 5, which shows that the observed groundwater-level changes are significantly smaller than those predicted from the coseismic strain. The reason is not obvious. Such tendency, however, was seen in the case of the 2000 volcanic eruption of Usu Volcano. Strain change during the volcanic eruption was calculated to be $10^{6}-10^{5}$ contraction by the groundwater-level change in DT1, which is consistent or one-order smaller than those caused by magma movement and predicted by the observation results of crustal deformation (Sato et al., 2002). There is a possibility that the strain sensitivities of groundwater level, which is calculated using tidal strain of about $10^{8}$, are not linear until a large strain of $10^{6}-10^{5}$ is reached.

In contrast, OBK2 is plotted above the line of $Y=10 X$ in Fig. 5, which indicates that the observed groundwater-level change are significantly larger than the theoretical change. Such tendency was also detected in Wariishi. The observed flow-rate change is $3 \mathrm{~L} / \mathrm{mm}$. However, the flow-rate change predicted by coseismic strain is only $0.03 \mathrm{~L} / \mathrm{min}$. The amplitude of the oscillation in OBK2 was the largest in the wells shown in Fig. 2, which may affect groundwater level to increase.

The 5 wells are plotted between $Y=0.1 X$ and $Y=10 X$ in Fig. 5, which are KNM, OBK1, TNN, TKB3 and KWNO. Koizumi et al. (2002) presented a similar figure as Fig. 5 using data of the 2001 Geiyo earthquake, and discussed the relationship between the observed changes and the theoretical ones. The result shows that the 8 wells were plotted between the two lines. In comparison of the both figures, KNM and OBK1 are commonly plotted between the two lines. In Fig. 5, the two wells are located nearest from the line of $Y=X$, which indicates that the groundwater level finely responds to the coseismic strain.

As for the other changes such as the long-period oscillation and preseismic increases observed in DT1 and DT2, the causes are not obvious. These changes, however, are very similar in the both wells, for example the dominant periods of the oscillations, 39 and 53 minutes, are same and the starting time and amount of the preseismic increases are also almost identical (Fig. 2(a)). Because the wells are located 4 $\mathrm{km}$ apart each other, these changes are not due to local factors but to broad-based phenomena.

There is a possibility that the long-period oscillation is as-

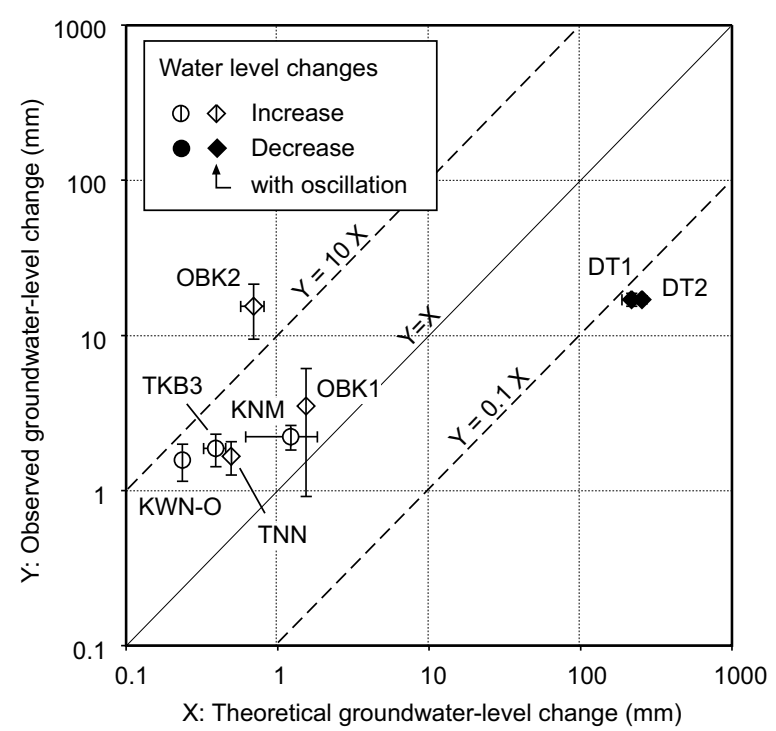

Fig. 5. Comparison of the theoretical coseismic groundwater-level changes to the observed ones.

sociated with tsunami, which is supported by the following two facts. One is that the observed tsunami in the Muroran tidal observatory started one hour after the earthquake and had a dominant period of about one hour (Fig. 2(a)). Second is that the amplitude of the oscillation in DT2 is larger than that of DT1. The DT2 well is located at shorter distance from seashore, $0.6 \mathrm{~km}$ than DT1 of $1.5 \mathrm{~km}$. Furthermore, the screened depth of DT2 is shallower than DT1 (Table1). Thus, it is concluded that sea-level changes due to the tsunami are easier to affect groundwater level in DT2 than DT1.

Acknowledgments. We are grateful to many people for the help to our observation at the wells. We also appreciate valuable comments by two anonymous referees.

\section{References}

Akita, F. and N. Matsumoto, Coseismic groundwater level changes in hot spring wells in Hokkaido induced by four earthquakes larger than M7.5 between 1993 and 1994, Jishin (J. Seismol. Soc. Japan), 53, 193-204, 2001 (in Japanese with English abstract).

Geographical Survey of Institute, http://www.gsi.go.jp/WNEW/ PRESS-RELEASE/2003/0926-2.htm, 2003 (in Japanese).

Igarashi, G. and H. Wakita, Tidal responses and earthquake-related changes in the water level of deep wells, J. Geophys. Res., 96, 4269-4278, 1991.

Japan Meteorological Agency, Seismological Summary, Newsletter Seismol. Soc. Japan, 15, 16-26 (in Japanese).

Koizumi, N., E. Tsukuda, M. Takahashi, T. Sato, N. Matsumoto, H. Ito, 
Y. Kuwahara, A. Cho, and T. Sato, Groundwater level observation of Geological Survey of Japan in and around the Kinki district, Japan for earthquake prediction research, J. Balneol. Soc. Japan, 49, 18-33, 1999 (in Japanese with English abstract).

Koizumi, N., Y. Kitagawa, M. Takahashi, T. Sato, N. Matsumoto, H. Ito, Y. Kuwahara, A. Cho, and T. Sato, Changes in groundwater level and crustal strain in and around the Kinki district related to the 2001 Geiyo Earthquake, Jishin (J. Seismol. Soc. Japan), 55, 119-127, 2002 (in Japanese with English abstract).

Matsumoto, K., T. Sato, T. Takanezawa, and M. Ooe, GOTIC2: A program for computation of oceanic tidal loading effect, J. Geodetic Soc. Japan, 47, 243-278, 2001.

Matsumoto, N., T. Sato, N. Matsushima, F. Akita, T. Shibata, and A. Suzuki, Hydrological anomalies associated with crustal deformation before the 2000 eruption of Usu volcano, Japan, Geophys. Res. Lett., 29, 10.1029/2001GL013968, 2002.

Naito, H. and S. Yoshikawa, A program to assist crustal deformation analysis, Jishin (J. Seismol. Soc. Japan), 52, 101-103, 1999 (in Japanese with English abstract).

Okada, Y., Internal deformation due to shear and tensile faults in a halfspace, Bull. Seismol. Soc. Am., 82, 1018-1040, 1992.

Roeloffs, E., Hydrologic precursors to earthquake: A review, Pure Appl. Geophys., 126, 177-209, 1988.

Roeloffs, E., Poroelastic techniques in the study of earthquake-related hydrologic phenomena, in Advances in Geophysics, edited by R. Dmowska, pp. 135-195, Academic Press, San Diego, 1996.

Sato, T., H. Wakita, K. Notsu, and G. Igarashi, Anomalous hot spring water changes: Possible precursors of the 1989 volcanic eruption off the east coast of the Izu Peninsula, Geochem. J., 26, 73-83, 1992.

Sato, T., N. Matsumoto, F. Akita, T. Shibata, A. Suzuki, N. Matsushima, and M. Takahashi, Anomalous groundwater-level changes in Data City associated with the 2000 eruption of Usu Volcano, Kazan (Bull. Volcanol. Soc. Japan), 47, 171-176, 2002 (in Japanese with English abstract).

Takahashi, M., N. Koizumi, T. Sato, N. Matsumoto, H. Ito, Y. Kuwahara, A. Cho, and T. Sato, Changes in groundwater level and crustal strain in and around the Kinki district related to the Western Tottori Earthquake, Jishin (J. Seismol. Soc. Japan), 55, 75-82, 2002 (in Japanese with English abstract).

Tamura, Y., T. Sato, M. Ooe, and M. Ishiguro, A procedure for tidal analysis with a Bayesian information criterion, Geophys. J. Int., 104, 507-516.

Wakita, H., Water wells as possible indicators of tectonic strain, Science, 189, 553-555.

Yamanaka, Y. and M. Kikuchi, Source process of the recurrent Tokachioki earthquake on September 26, 2003, inferred from teleseismic body waves, Earth Planets Space, 55, e21-e24, 2003.

T. Sato (e-mail: sugar@ni.aist.go.jp), N. Matsumoto, Y. Kitagawa, N. Koizumi, M. Takahashi, Y. Kuwahara, H. Ito, A. Cho, T. Sato, K. Ozawa, and S. Tasaka 